\title{
Cohabitation, marriage and relationship stability
}

\section{IFS Briefing Note BN107}

Alissa Goodman

Ellen Greaves

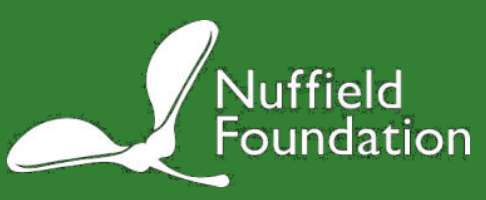




\title{
Cohabitation, marriage and relationship stability
}

\author{
Alissa Goodman and Ellen Greaves ${ }^{1}$
}

\author{
Institute for Fiscal Studies
}

\section{Introduction}

Does being married rather than cohabiting lead to more stability in relationships between parents? This assertion is made in the government's recent State of the Nation report: ${ }^{2}$

Around 3 million children in the UK have experienced the separation of their parents. This is partly attributable to a rise in cohabitation, given the increased likelihood of break-up for cohabiting couples relative to married couples.

In this Briefing Note, we critically appraise this statement, building on analysis contained in our recent IFS Commentary, Cohabitation, Marriage and Child Outcomes. ${ }^{3}$

Our findings suggest that while it is true that cohabiting parents are more likely to split up than married ones, there is very little evidence to suggest that this is due to a causal effect of marriage. Instead, it seems simply that different sorts of people choose to get married and have children, rather than to have children as a cohabiting couple, and that those relationships with the best prospects of lasting are the ones that are most likely to lead to marriage. Our analysis suggests, therefore, that if more cohabiting parents decide to get married, it is very unlikely that a significant number would become more likely to stay together. It

\footnotetext{
${ }^{1}$ This Briefing Note has been funded by the Nuffield Foundation as part of a wider project, grant number CPF/37467. The Nuffield Foundation is an endowed charitable trust that aims to improve social well-being in the widest sense. It funds research and innovation in education and social policy and also works to build capacity in education, science and social science research. The Nuffield Foundation has funded this project, but the views expressed are those of the authors and not necessarily those of the Foundation. More information is available at http://www.nuffieldfoundation.org.
}

\footnotetext{
2 Page 50 of HM Government, State of the Nation Report: Poverty, Worklessness and Welfare Dependency in the UK, May 2010, ref: 401172/0510.

${ }^{3}$ http://www.ifs.org.uk/publications/4823.

In that report, we considered whether young children's cognitive or social and emotional development is causally affected by the formal marital status of their parents. Our main conclusion from that work was that neither young children's cognitive development nor their social and emotional development appears to be significantly affected by the formal marital status of their parents, once differences in other characteristics between married and cohabiting parents are taken into account.
} 
also means that it is highly unlikely that the increasing rate of childbearing among cohabiting couples has caused an increased likelihood of break-up among parents.

This issue is important, because enhanced relationship stability is often considered to be one of the key pathways through which formal marriage between parents might lead to better outcomes for children. ${ }^{4}$ To establish that this is the case, however, it needs to be clearly shown that marriage itself promotes relationship stability, rather than it simply being the case that people who are more likely to stay together are the ones who get married. We attempt to address this issue directly in this note. Moreover, it also needs to be shown that family breakdown is detrimental to children - another issue where it is important to establish causal relationships carefully rather than to rely on statistical associations (though this is beyond the scope of this note).

This Briefing Note proceeds as follows. We first outline some basic statistics from the Millennium Cohort Study (MCS), which is a national longitudinal study of a large sample of children born in 2000 and their parents. We show the likelihood of relationship breakdown among the parents of young children, comparing separation rates among married and cohabiting couples. We then discuss whether any such differences can be attributed to a causal effect of marriage itself, or whether they are more likely to arise instead from the underlying differences between the kinds of people who choose marriage, rather than cohabitation, as the relationship form in which to raise their children. We draw some conclusions in Section 3.

\section{Are cohabiting parents more likely to separate than married parents?}

\section{Existing UK evidence}

A number of recent UK papers have documented the association between marriage and relationship stability. Using the Millennium Cohort Study (the same data source that we employ in our own work), Benson (2009) finds that around $27 \%$ of couples that were cohabiting when their child was born have separated by the time the child is aged 5 , compared with $9 \%$ of couples that were married when their child was born. ${ }^{5}$

\footnotetext{
${ }^{4}$ For example: 'The statistics indicate that marriages are far more likely to provide a stable environment for adults and children than cohabitation and are more resilient when the family is facing a crisis or stressful life event such as childbearing' (page 11 of Social Policy Justice Group, The State of the Nation Report: Fractured Families, Centre for Social Justice, London, 2006).

${ }^{5} \mathrm{H}$. Benson, Married and Unmarried Family Breakdown: Key Statistics Explained, Bristol Community Family Trust, 2009.
} 
Kiernan and Mensah (2010), also using the same data source, document more detailed trajectories of couples that are married or cohabiting when their child is born. ${ }^{6}$ They find that $88.1 \%$ of parents who were married at the time of the birth of their child are 'stable' at least until their child is 5 years old, while $2.1 \%$ experience periods of separation but are together when their child is aged 5, $7.6 \%$ are lone parents when the child is aged 5 and $2.1 \%$ have re-partnered. By contrast, around $66.6 \%$ of couples that were cohabiting at their child's birth are classified as 'stable' at age 5 (43.4\% remain cohabiting and $23.2 \%$ get married), $5.7 \%$ experience periods of separation, $20.5 \%$ are lone parents and $7.3 \%$ have re-partnered.

These findings are corroborated in our own work. Table 1 shows the proportion of cohabiting and married relationships in the Millennium Cohort Study that have broken down by the time a child has reached the ages of 3 and 5 .

\section{Parental separation by the age of 3}

The first column of Table 1 shows that there is a significant difference in the probability that a couple will split up for a month or more by the time their child is 3 years old, between couples that were cohabiting and couples that were married when their child was born: $26 \%$ of couples that were cohabiting when their child was born experience some period of separation before their child is 3 years old, compared with just 7\% of married couples. ${ }^{7}$ There are a number of other ways in which we can express this difference: cohabiting couples are around four times more likely to experience a period of separation of at least a month by the time their child is aged 3 (this ratio of probabilities is sometimes referred to as the relative risk), whilst the odds of separation for cohabiting couples are five times larger than the odds for married couples (the odds ratio). In absolute terms, the difference in probabilities is 19.7 percentage points.

The second column of Table 1 shows the equivalent statistics for the number of couples that are not living together when the MCS survey is taken around the time the child is aged 3. This column represents a more 'snapshot' view of a couple's stability, as it does not take account of any other periods of separation.

\footnotetext{
${ }^{6} \mathrm{~K}$. Kiernan and F. Mensah, 'Partnership trajectories, parent and child well-being', in K. Hansen, H. Joshi and S. Dex (eds), Children of the 21st Century: The First Five Years, Policy Press, Bristol, 2010.

${ }^{7}$ These periods of separation should not be periods of separation for work or other nonrelationship-based reasons. For example, main respondents to the survey at the age 3 survey (MCS wave 2) were asked whether they had been looking after the cohort member 'as a lone parent for a period of a month or more at any time since [the cohort member] was 9 months old', to which they could respond 'yes' or 'no'. The interviewer was instructed to code 'no' if they were living as a lone parent because their partner was temporarily away (for example, for work reasons). If the respondent answered 'yes', they were prompted to provide dates for each period of lone parenthood they experienced.
} 
Comparison of the first and second columns shows that while $26 \%$ of couples that were cohabiting when their child was born experience some period of separation before their child is aged 3, only $20 \%$ are living apart at the date of the age 3 survey. Column 1 is therefore a broader measure of stability: 6\% more of cohabiting couples split up temporarily than we observe at a 'snapshot' point in time.

\section{Parental separation by the age of 5}

The last column of Table 1 shows that the percentage of couples that are no longer living together when their child is aged 5 is greater than that when the child is aged 3, being at $27 \%$ for couples that were cohabiting when their child was born and at $9 \%$ for couples that were married when their child was born. ${ }^{8}$

Again there are a number of other ways in which we can express this difference by the age of 5 : for example, cohabiting couples are around three times more likely to have split up by the time their child is aged 5 .

Table 1. Descriptive statistics for the percentage of couples that experience some kind of separation, by marital status when their child was born

\begin{tabular}{lccc}
\hline & $\begin{array}{c}\text { Couple live } \\
\text { separately for at } \\
\text { least a month before } \\
\text { their child is aged 3 }\end{array}$ & $\begin{array}{c}\text { Couple are not living } \\
\text { together when child } \\
\text { is aged 3 }\end{array}$ & $\begin{array}{c}\text { Couple are not living } \\
\text { together when child } \\
\text { is aged 5 }\end{array}$ \\
\hline Cohabiting at child's birth & $26 \%$ & $20 \%$ & $27 \%$ \\
Married at child's birth & $7 \%$ & $5 \%$ & $9 \%$ \\
Relative risk ratio & 3.92 & 4.10 & 2.90 \\
Odds ratio & 4.97 & 4.86 & 3.59 \\
Difference in probability & 19.69 & 14.99 & 17.40 \\
\hline
\end{tabular}

\section{Notes:}

The percentage of couples is weighted by non-response weights.

The relative risk is defined as the proportion of couples that were cohabiting when their child was born that split up $\left(P_{c}\right)$, divided by the proportion of couples that were married when their child was born that split up $\left(P_{m}\right)$. The relative risk is therefore a ratio of the 'risk' in each population $\left(P_{c} / P_{m}\right)$.

The odds ratio is the ratio of the odds of splitting up for couples that were cohabiting and for those that were married when their child was born. For cohabiting couples, the odds of splitting up are the probability that a couple that was cohabiting when their child was born splits up, divided by the probability that the couple does not split up $\left(P_{c} /\left[1-P_{c}\right]\right)$, and equivalently for couples that were married when their child was born. The odds ratio is therefore $P_{c} /\left[1-P_{c}\right] / P_{m} /\left[1-P_{m}\right]$.

Source: Millennium Cohort Study.

\footnotetext{
${ }^{8}$ Unfortunately, we cannot construct a 'broader' measure of stability up to the age of 5 that is the equivalent of the first column (in other words, that takes into account all periods of separation up until the child is aged 5) because of the questionnaire's more limited content at age 5 .
} 
However, these statistical associations do not tell us anything about whether marriage itself has protective effects. In the following subsections, we try to assess the extent to which the differences in stability between couples that are married and those that are cohabiting when their child is born are due to marriage itself, or largely due to pre-existing characteristics of the couples.

\section{Cohabiting parents differ in many other ways from married parents}

There are many important differences in the characteristics of couples that have chosen to cohabit or marry at the time of their child's birth. It could be that it is pre-existing differences, rather than marriage itself, which account for some of the difference in the rate of separation for married and cohabiting couples.

The differences that we are able to observe within our study (based on the MCS) include characteristics of the couple such as their education, occupational status and income, their housing tenure and the relationship quality of the couple (measured early in the child's life). These differences are documented fully in our Commentary cited above at footnote 3 . In summary, the analysis shows that couples are more likely to be married rather than cohabiting if:

- the mother is of Indian, Pakistani or Bangladeshi ethnicity;

- the mother is religious;

- the mother's parents did not separate;

- there are no children of previous partners in the household;

- the mother and father have high levels of education;

- the parents own their own home;

- the couple lived together for longer prior to the child's birth;

- the pregnancy was planned;

- the mother was 20 or older when her first child was born;

- there is more than one child in the household;

- the parents have a higher relationship quality when the baby is 9 months old.

There are also likely to be further underlying differences between married and cohabiting relationships that cannot be observed even within a detailed study such as the MCS. These 'unobservable' characteristics might include the couple's underlying sense of love and commitment to each other, level of conflict and methods for dealing with problems. 


\section{Does marriage improve relationship stability between parents?}

The preceding discussion should help clarify our question: is it marriage per se that improves relationship stability between parents, or do differences in the incidence of relationship instability simply reflect the other underlying differences - whether observed or unobserved - between married and cohabiting parents that we have discussed?

In this section, we attempt to address this question simply by controlling for a number of observable differences between married and cohabiting parents. In our recent Commentary, we described with great care our methodology and choice of control variables, noting that by using this simple methodology we may either:

(i) overstate the true effects of marriage, if there are important unobserved characteristics of cohabiting compared with married relationships that we cannot take into account; for example, if inherently less loving or less committed relationships are both less likely to result in marriage and more likely to break down, but we do not control for such unobserved characteristics, this will lead to an overstatement of the effects of marriage; ('correlated unobservables')

or:

(ii) understate the true effects of marriage on relationship stability, if we control for characteristics that are significantly influenced by marriage itself; for example, if marriage itself leads to improved self-reported relationship quality, which in turn leads to a lower likelihood of relationship breakdown, and we control for this in our analysis, this could lead to an understatement of the effects of marriage. ('endogenous regressors')

We do not have any estimation strategy to deal with the first potential source of bias. However, in order to assess the possible magnitude of bias arising from the second, in the following analysis we group variables based on the extent to which we judge that they reflect pre-existing characteristics of the parents, compared with the extent to which they might plausibly be influenced by the decision to marry itself.

In Table 2, we present differences in the probability of relationship breakdown between married and cohabiting parents after we have controlled for a wide range of other parental and relationship characteristics, some of which clearly pre-date the choice of whether to get married. We group our potential control variables according to whether they are likely simply to reflect the type of parents who decide to get married (columns A-D in the table); or whether they might instead also be affected by the decision to get married, and therefore 'pre- 
exist' marriage but could also be affected by it (columns E-H). Controlling for the former is uncontroversial and should get us closer to the 'causal' effect of marriage on relationship stability. In controlling for the latter, we risk 'overcontrolling' for the indirect effects of marriage, and hence any benefits of marriage. (Empirically assessing the extent to which any such indirect effects exist is very difficult, though in our recent Commentary we attempted to provide some informed judgement on this, based on a wide social science literature.)

Table 2 shows results from some multivariate regression analyses assessing the difference between married and cohabiting parents in the probability of the relationship splitting up by the time the child is aged 3 and 5 . Each row shows a different outcome variable, capturing each of the measures of relationship stability we set out in Table 1 . In each column of Table 2 , we add successive controls to our analysis; the variables 'controlled for' in each model are listed in the bottom half of the table. ${ }^{9}$

The top panel of results shows the average percentage point difference in the likelihood of parental separation by the ages of 3 and 5 associated with being born to a cohabiting rather than a married couple. It does this by showing the marginal effects on an indicator of whether the couple is cohabiting rather than married, estimated from a series of probit regressions. The lower panel of results shows corresponding odds ratios (estimated using logit regressions), which are interpreted as the comparison of the odds of separation for cohabiting and married couples. ${ }^{10}$

Controlling for those characteristics that are fixed over time - as we do in columns B through D - is uncontroversial (and necessary if a convincing causal argument is to be made). As the decision to marry has no impact on characteristics such as parents' ethnicity and own family background, it is straightforward to separate the effect of these factors on relationship stability

\footnotetext{
${ }^{9}$ In column B, we control for the child's gender and year and month of birth. Column C additionally controls for the mother's ethnicity, place of birth and religion, and her mother's place of birth; column $D$ for whether the mother was in care or in a separated family when she was a child and whether there are children from previous relationships in the current family; column E for the mother's and father's levels of education when the child is 9 months old; column $\mathrm{F}$ for the father's occupational status when the child is 9 months old and for housing tenure, household income and the mother's and father's employment when the child is 9 months old; column G for the mother's and father's ages when they had their first child, whether the child was a multiple birth, the child's birth order, how long the couple had lived together before the birth, whether the pregnancy was planned and the frequency of contact with the maternal grandmother. Finally, column $\mathrm{H}$ controls additionally for the couple's relationship quality measured when the child is 9 months old.

${ }^{10}$ Note that the differences in the likelihood of separation between cohabiting and married couples - set out in both probabilities and odds ratios - before any characteristics are controlled for, shown in column A, match those already presented in Table 1.
} 
from the impact of marriage. Once we do this in our analysis, we find that the difference in the likelihood of splitting up between married and cohabiting parents is slightly reduced, but remains large and statistically significant. For example, controlling for the child's gender and year and month of birth and the mother's ethnicity, immigration status, religion and background, couples that were cohabiting when their child was born are 16.7 percentage points more likely to experience a period of separation before their child is 3 years old than couples that were married when their child was born. We can also express this as an odds ratio of 4.3, meaning that the odds of experiencing a period of separation for cohabiting couples are over four times the odds of experiencing a period of separation for married couples.

A second set of variables could possibly affect the timing of the decision to get married, but still in some sense 'pre-date' marriage, so that they are unlikely to be an effect of marriage itself. An example would be maternal education: mothers who opt for more education are likely to complete their education before they have children and are more likely to be married, but this is unlikely to mean that marriage 'causes' the higher education levels. Indeed, our previous Commentary noted that $98 \%$ of mothers in the MCS who were married at the time of their child's birth had left full-time education before they got married.

Other characteristics of parents that we control for in subsequent columns ( $\mathrm{E}$ through $\mathrm{H}$ ) are likely to reflect the different sorts of people who choose to cohabit rather than to get married in the first place, but may also be affected by the couple's decision to marry (to a larger extent than education). Controlling for these characteristics in seeking to estimate the causal effect of marriage on relationship stability is potentially more controversial. For example, parents' socio-economic status, some measures of their family structure, and the quality of their relationship early in their child's life are likely to affect the choice to get married but may also be affected by it. By controlling for these characteristics, in columns $\mathrm{E}$ through $\mathrm{H}$, there is therefore a chance that we might inadvertently 'control away' some of the indirect effects of marriage. By not controlling for them at all, however, we would certainly risk overstating the effects of marriage instead.

To give more specific examples:

- Housing tenure may largely reflect pre-existing wealth, but the commitment of marriage may also affect couples' housing tenure decisions.

- The quality of the parents' relationship when the child is 9 months old presents us with another even clearer example of the difficulty in distinguishing between pre-existing characteristics of the parents and characteristics that might also be affected by the decision to marry. 
If a couple has a better relationship quality or a higher level of communication, they may be more likely to get married in the first place, and this underlying factor might also mean that they are likely to stay together in the future, irrespective of their decision to marry. In this case, marriage does not cause the lower likelihood of separation - this is due instead to the preexisting high relationship quality of the couple that led both to their marriage and to the stability of their relationship. If we did not include this variable in our analysis, we would overstate the true impact of marriage.

On the other hand, if the act of marriage were additionally to have a positive impact on the couple's relationship quality, and this in turn had an additional positive impact on their relationship stability, then our final estimate could provide an underestimate of the true impact of marriage if this variable were included in our regressions.

Columns $\mathrm{E}$ through $\mathrm{H}$ of Table 2 show that once we control for these extra variables in our analysis, we find that the difference in the likelihood of separation associated with cohabiting rather than being married decreases very substantially. After controlling for all the variables in our model, couples that were cohabiting when their child was born are only 2.1 percentage points more likely to experience a period of separation of a month or more by the time the child is aged 3 (compared with 19.7 percentage points in the 'raw' specification of column A, when no additional variables are controlled for). We can also express this as an odds ratio of 1.5 , meaning that the odds of experiencing a period of separation are now around 50\% larger for cohabiting couples than for married couples - this is in fact a small difference compared with the odds ratio related to the raw specification in column A of nearly 5 (or in other words representing an increase in odds of nearly $400 \%$ ).

Looking at column $\mathrm{H}$, the difference in the likelihood of a couple being separated when the child is aged 5 is even smaller and statistically insignificant (compared with a difference of around 17 percentage points in our column A 'raw' specification), once all the variables in our model are controlled for.

It is worth taking particular note of the effect of adding relationship quality into our model specification, seen by comparing columns $\mathrm{G}$ and $\mathrm{H}$ of Table 2 . After accounting for all the other characteristics in the model, relationship quality does reduce the difference in the likelihood of separation between cohabiting and married couples, though the magnitude of this reduction is in fact relatively small. 


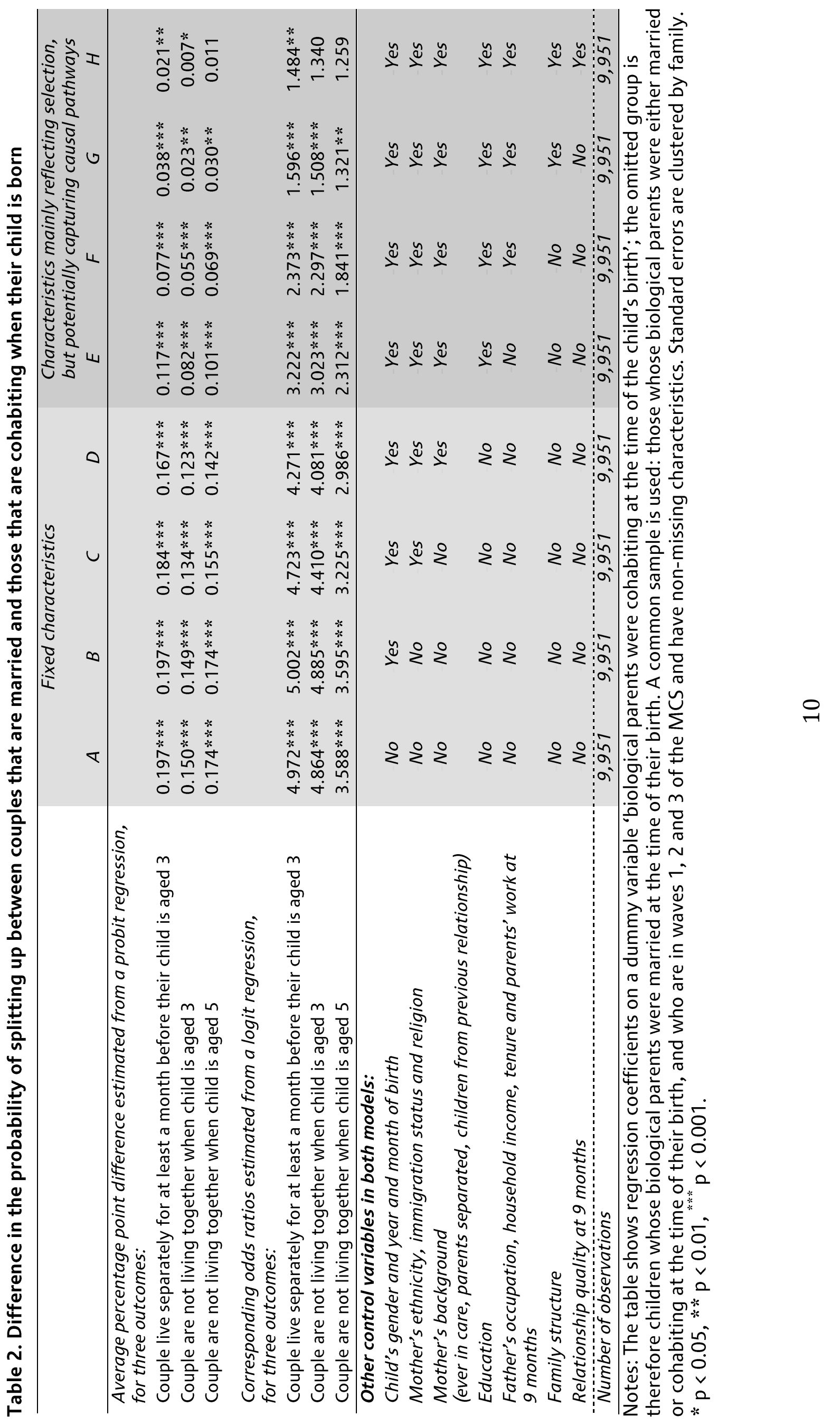




\section{What other factors are related to relationship stability?}

We briefly detail below the relationship between the other characteristics included in our model and parents' relationship stability:

- ethnicity: the mother being Black (Caribbean or African) is associated with a greater probability of separation and the mother being Indian with a lower probability of separation (relative to being White);

- the mother being a Christian (relative to having no religion) has a negative association with the probability of separation;

- the mother's own parents having separated has a positive association with the probability of separation;

- the mother having a low level of education has a positive association with the probability of separation;

- having a low household income has a positive association with the probability of separation;

- not owning their own home has a positive association with the probability of separation;

- the mother being young (in particular having a teenage pregnancy) has a positive association with the probability of separation;

- having an unplanned pregnancy has a positive association with the probability of separation;

- higher relationship quality of the parents reported when the child is 9 months old has a negative association with the probability of separation.

\section{Conclusions}

Relationship stability is often considered to be one of the key pathways through which formal marriage between parents might lead to better outcomes for children. In our recent Commentary, ${ }^{11}$ we concluded that young children's cognitive development and their social and emotional development do not appear to be significantly affected by the formal marital status of their parents, once differences in other characteristics between married and cohabiting parents are taken into account. This

\footnotetext{
${ }^{11}$ A. Goodman and E. Greaves, Cohabitation, Marriage and Child Outcomes, Commentary 114, Institute for Fiscal Studies, London, 2010, http://www.ifs.org.uk/publications/4823.
} 
conclusion in itself suggests that marriage is unlikely to have the 'protective' effects on children that many contend, either through a decreased likelihood of relationship breakdown or by some other channel. However, in that work, we did not explicitly examine directly the relationship between marriage and relationship breakdown.

In this Briefing Note, we therefore extend our analysis by documenting the difference in the likelihood of separation for couples that are either married or cohabiting when their child is born. Across a number of measures, we have shown that cohabiting parents are more likely to separate than married ones. However, the difference in the likelihood of separation between couples that are married and those that are cohabiting when their child is born is substantially reduced once we account for differences in the characteristics of the parents in these two groups. This suggests that much of the difference in relationship stability between married and cohabiting parents is due to pre-existing differences between the kinds of people who get married before they have children and those who cohabit. In particular, differences in their education, socio-economic status and some aspects of family structure (such as whether the mother had her first child at a young age and whether the pregnancy was planned) explain a large amount of the correlation between marital status when a child is born and the likelihood of separation. We therefore find no strong evidence that there is a substantial causal link between parents being married when their child is born and a lower probability of relationship separation.

We caution, however, that our analysis cannot provide evidence on the true causal relationship between marriage or cohabitation and the likelihood of separation. On the one hand, the characteristics we have included in our analysis may be questioned by some, who think that they 'control away' those channels through which marriage has a positive effect. In this case, our analysis would understate the impact of marriage on the probability of separation. On the other hand, we think it is unlikely that we can fully account for all of the pre-existing differences between married and cohabiting couples, despite the richness of the Millennium Cohort Study data we use. There are still likely to be unobservable characteristics of the couples - such as their feelings about commitment more generally, their lifestyle and their attitude to children - that are formed prior to the decision to get married. If these characteristics are correlated with a lower probability of separation, then it is likely that our current analysis overstates the impact of marriage on the probability of separation. ${ }^{12}$

\footnotetext{
${ }^{12}$ We hope to provide further evidence on this issue using the British Cohort Study, which has more detailed information on the parents' relationship prior to the birth of
} 
Given the possibility that there exists a positive association between cohabitation when a child is born and subsequent separation, it is prudent to return to consider the effect that relationship instability may have on child outcomes. This is another issue where it is important to carefully establish causal relationships rather than to rely on statistical associations. Although this is beyond the scope of this briefing note, the results underlying our earlier Commentary provide some evidence on this issue ${ }^{13}$, while for more in depth discussion of the literature in this area see, for example, Amato (2001) ${ }^{14}$ and Mooney et al (2009) ${ }^{15}$.

the child, and so will hopefully allow us to come closer to establishing whether there is a causal impact of marriage on relationship stability.

${ }^{13}$ Interestingly the results underlying our earlier Commentary gave no strong indication that differences in relationship stability between couples that were married and those that were cohabiting when the child was born had an impact on their young child's cognitive or social and emotional development, once we had accounted for other characteristics of the parents. See tables A3-A6 in the appendix of that Commentary.

${ }^{14} \mathrm{P}$. Amato, 'Children of divorce in the 1990s: an update of the Amato and Keith (1991) meta-analysis', Journal of Family Psychology, 15, 355-370, 2001.

${ }^{15}$ A. Mooney, C. Oliver and M. Smith, Impact of Family Breakdown on Children's Well-Being: Evidence Review, Research Report DCSF-RR113, Department for Children, Schools and Families, London, 2009. 